\title{
Study on Seismic Coefficient Calculation Method of Slope Seismic Stability Analysis
}

\author{
Pai Lifang $\mathbb{D}^{1}{ }^{1}$ Wu Honggang $\mathbb{D}^{2},{ }^{2}$ Yang Tao, ${ }^{3}$ and Zhong Feifei ${ }^{4}$ \\ ${ }^{1}$ China Academy of Railway Sciences, Beijing 100081, China \\ ${ }^{2}$ Northwest Research Institute Co., Ltd. of C.R.E.C., Lanzhou, Gansu 730000, China \\ ${ }^{3}$ School of Civil Engineering, Southwest Jiaotong University, Chengdu, Sichuan 610031, China \\ ${ }^{4}$ College of Social Development and Public Administration, Northwest Normal University, Lanzhou, Gansu 730000, China \\ Correspondence should be addressed to Wu Honggang; 271462550@qq.com
}

Received 12 April 2021; Revised 28 July 2021; Accepted 11 August 2021; Published 30 August 2021

Academic Editor: Said Elias

Copyright (C) 2021 Pai Lifang et al. This is an open access article distributed under the Creative Commons Attribution License, which permits unrestricted use, distribution, and reproduction in any medium, provided the original work is properly cited.

\begin{abstract}
In this paper, a pseudostatic seismic coefficient evaluation method for slope dynamic stability analysis was explored with Yushu Airport Road 3\# landslide as a typical engineering case, and the shaking table test and numerical calculation were performed during the exploration. The loading waveform was selected as Yushu wave, and the acceleration time-history of seismic waves was measured and analyzed, revealing the failure mode of slopes. Based on the rigid-body limit equilibrium theory, the instantaneous additional seismic forces of each block and the time-history landslide stability coefficient were calculated. According to the timehistory of the landslide, dynamic stability coefficients were calculated. Subsequently, we proposed a pseudostatic seismic coefficient evaluation method and discussed the seismic coefficient slope dynamic stability analysis. The results showed that as the vibration frequency rose, the average acceleration and the residual displacement of the slope decreased, but the slope grew more dynamically stable. With the proposed method, we calculated the period of slope seismic action to be $0.126 \mathrm{~s}$ and the average maximum acceleration to be $0.156 \mathrm{~g}$, which was close to the designed ground motion acceleration of $0.15 \mathrm{~g}$. Besides, we calculated the safety factor of landslides under earthquake to be $0.93 \sim 0.97$, which was close to that obtained from the building code method and in accordance with the present seismic deformation and failure mode of landslides. Moreover, the results obtained from the method of nuclear power plant specification were relatively small compared to other specification methods. The research is significant because it provides a new idea for the evaluation of seismic landslide stability in practical engineering.
\end{abstract}

\section{Introduction}

Slope stability involves many engineering fields, including geotechnical engineering, road and bridge engineering, mine engineering, and construction engineering [1]. Specifically, the rock-soil slope is a natural geological body generally cut by multiple groups of faults, joints, fissures, and weak zones, leading to a weakening surface. With external factors such as the slope angle, groundwater, and seismic force, rock-soil slopes slide along the weakening surface and become unstable, resulting in slope destruction and consequent casualties and economic losses under them. Accidents caused by slope destruction are very common in engineering [2].
Slope stability has always been an important research content in geotechnical engineering, and the accuracy of slope stability evaluations could determine whether a slope engineering project succeeds or not. At present, there are various methods for slope stability evaluation, including the pseudostatic method, the Newmark method, and the dynamic finite element time-history method [3]. As mathematical methods and computer technologies advance, slope stability analysis has also made significant progress. Newmark [4] proposed to take seismic permanent deformation as an evaluation index of seismic stability. Such an idea was simple in theory and convenient in the calculation and had been greatly improved and developed [5]. However, the Newmark method and its derivatives do not consider critical 
failure criteria of deformation, making them not so desirable. On the one hand, dynamic finite element time-history analysis applies the dynamic stress at each moment to the static stress. Following that, the method obtains the safety factor at each moment and the factor's time-history curve, transforming a dynamic problem into a static one so that the static method could be used to solve the safety factor of the dynamic slope stability. To a certain extent, this method considers the dynamic effect of the slope, making it a favored and convenient strategy to analyze the evolution of the dynamic slope stability. Nevertheless, like all finite element analysis methods, it also had some shortcomings, such as a complicated theory of a dynamic constitutive model, as well as difficulties to select calculation parameters and determine the dynamic boundary. As a result, it is not the most applicable method in engineering design.

In 1950, Terzaghi [6] proposed the pseudostatic method for the first time to calculate the seismic stability coefficient, and the method becomes the most widely used one in slope seismic stability analysis due to its simple principles and clear concepts of stability coefficient indexes. At present, the pseudostatic method is the most widely used method in slope seismic stability analysis, which has accumulated a lot of engineering experience. In an applied research of the slope field, Utili and Abd [7] analyzed the influence of vertical acceleration directions on slope stability based on the upper bound theorem of limit analysis and the pseudostatic method, and they determined the yield seismic coefficients. Li et al. [8] derived the expressions of safety factors of fractured slopes under earthquake by an energy equation established from upper limit analysis and pseudostatic analysis based on the nonlinear Mohr-Coulomb failure criterion. Nian et al. [9] and Jadar and Ghosh [10] used the pseudostatic method to analyze the seismic stability of soil slopes strengthened by anchors and to determine the seismic bearing capacity of shallow foundations, respectively. Nimbalkar et al. [11] studied the seismic stability of reinforced soil with the pseudostatic method of nonlinear failure surface while considering horizontal and vertical seismic accelerations. Furthermore, based on the pseudostatic method, Izadi et al. [12] evaluated the influence of undrained shear strength on the seismic bearing capacity with the limit equilibrium method of the Coulomb failure mechanism. Since previous seismic designs of underground structures were based on elastic assumptions, Yang et al. [13] proposed an improved finite element method, new pseudostatic analysis without the elastic assumptions. In a word, the pseudostatic method has been widely used to evaluate the seismic bearing capacity and structural deformations.

However, in the pseudostatic method, the instantaneous seismic load is considered permanent, and the action direction points outside, which would only lead to calculation results that are overly conservative. Particularly, the selection of seismic coefficient is extremely critical in the pseudostatic method, and such selections are not unified (Table 1).

In a practical application, the pseudostatic method is generally used together with the limit equilibrium method for slope stability analysis [20]. The seismic inertia force acts on the mass center of the divided soil strip, and the horizontal inertia force is generally considered. In this way, commonly used limit equilibrium methods, such as the Swedish method [21] and the Bishop method [22], could be used for seismic slope pseudostatic analysis with little derivation. There are various methods to calculate the slope seismic force, leading to numerous evaluation results of slope dynamic stability. The current calculation method for horizontal seismic load takes the product of seismic coefficient and gravity as the horizontal seismic force, which is the foundation of a lot of slope calculation software, such as GeoStudio Slope and Rocscience_Slide [23-25].

Nevertheless, the author believe that traditional pseudostatic analysis methods fail to consider earthquake propagation features, and the results they produce are not satisfactory when applied directly to analyzing slopes. The reason for landslide instability is that the acceleration difference between the sliding body and the sliding bed, which comes into being when the seismic wave propagates in the rock and soil. In this paper, we took Yushu Airport Road 3\# landslide as a typical engineering case for shaking table tests and numerical calculations. The acceleration time-history data were obtained and analyzed, form which the slope failure mode was revealed. Based on the rigid-body limit equilibrium theory, the instantaneous additional seismic forces in each block and the landslide stability coefficient were calculated, and we proposed and discussed a pseudostatic seismic coefficient evaluation method for slope dynamic stability analysis.

\section{Overview of Yushu Airport Road 3\# Landslide}

Qinghai Yushu to Batang airport highway was located in the section of K821 +400 K840+580 of National Highway 214 , and the $3 \#$ landslide $(\mathrm{K} 823+600 \sim \mathrm{K} 824+400)$ belonged to the landslide caused by the Yushu Earthquake happened on April 14th, 2010. According to the landform and deformation characteristics of the landslide, the main sliding direction was determined to be $\mathrm{NE} 32^{\circ} \sim 42^{\circ}$, which was basically perpendicular to the line. The sliding belt was mainly composed of breccia with low clay or breccia content between different layers or different periods of time. It was mainly taupe and grayish black with medium density to density and moisture. This layer has been exposed in the drilling, and its distribution thickness was different. The maximum width of the landslide was $593 \mathrm{~m}$, the total length was about $190 \mathrm{~m}$, and the volume was $1.29 \times 10^{6} \mathrm{~m}^{3}$. The whole landslide was divided into three sliders, and each of which was divided into two stages, as shown in Figure 1.

2.1. Geological Structures and the Earthquake in Yushu. Yushu County is located in the belt-like Bayankala Mountains Seismic Zone in the central Tibetan Plateau earthquake subregion of the Qinghai-Tibet earthquake region, where the regional large fault zone is very powerful. In the belt-like zone, the neotectonics movement is strong, and the active fault zone expands primarily in NW and NNW directions. 
TABLE 1: Comparison of slope correlation criteria by the pseudostatic method.

\begin{tabular}{|c|c|c|c|}
\hline Number & Specification name & $\begin{array}{l}\text { Horizontal seismic } \\
\text { inertial force/ } F_{\mathrm{hi}}\end{array}$ & Instructions \\
\hline 1 & $\begin{array}{l}\text { Specification of seismic design for } \\
\text { highway engineering [14] }\end{array}$ & $C_{i} C_{z} K_{h} G_{s}$ & $\begin{array}{l}C_{i} \text { is the importance correction factor, which is } 0.6 \sim 1.7 . C_{z} \text { is the } \\
\text { comprehensive influence coefficient, which is } 0.25 . K_{h} \text { is the seismic } \\
\text { coefficient. } G_{s} \text { is the gravity of soil mass. }\end{array}$ \\
\hline 2 & $\begin{array}{l}\text { Specifications for seismic design of } \\
\text { hydraulic structures [15] }\end{array}$ & $a_{h} \xi G_{E i} a_{i} g$ & $\begin{array}{l}\xi \text { is the reduction coefficient of seismic effect, generally } 0.25 . G_{E i} \text { is } \\
\text { gravity, and } \alpha_{i} \text { is the dynamic distribution function distributed } \\
\text { along the height. As for the reduction coefficient } \xi \text { of seismic effect, } \\
\text { the provisions explain that it was mainly to bridge the difference } \\
\text { between the result of dynamic analysis based on the representative } \\
\text { value of designed seismic acceleration and the macroscopic seismic } \\
\text { damage phenomenon and to adapt to the seismic design practice of } \\
\text { existing projects at home and abroad. The coefficient was } \\
\text { determined based on the long-term accumulated practical } \\
\text { experience at home and abroad and belongs to the empirical } \\
\text { coefficient [16]. }\end{array}$ \\
\hline 3 & $\begin{array}{l}\text { Specifications for seismic design of } \\
\text { buildings [17] }\end{array}$ & $a_{1} G_{\mathrm{eq}}$ & $\begin{array}{l}a_{1} \text { is the horizontal seismic influence coefficient value of the basic } \\
\text { natural vibration period of the structure. } G_{\text {eq }} \text { is the equivalent total } \\
\text { gravity load of the structure. }\end{array}$ \\
\hline 4 & $\begin{array}{l}\text { Specifications for seismic design of } \\
\text { nuclear power plants [18] }\end{array}$ & & $\begin{array}{l}\text { When the pseudostatic method was used to check the seismic } \\
\text { stability of slopes, the ground motion acceleration at the center of } \\
\text { gravity of each unit was } 1.5 \text { times of the ground motion design } \\
\text { acceleration, which did not change with depth. }\end{array}$ \\
\hline 5 & $\begin{array}{l}\text { Specifications for seismic design of } \\
\text { railway engineering [19] }\end{array}$ & $\eta A_{g} m_{i}$ & $\begin{array}{l}\eta \text { is the horizontal seismic correction coefficient, which is } 0.25 . A_{g} \text { is } \\
\text { the peak acceleration of ground motion. } m_{i} \text { is the mass of the clods. }\end{array}$ \\
\hline
\end{tabular}

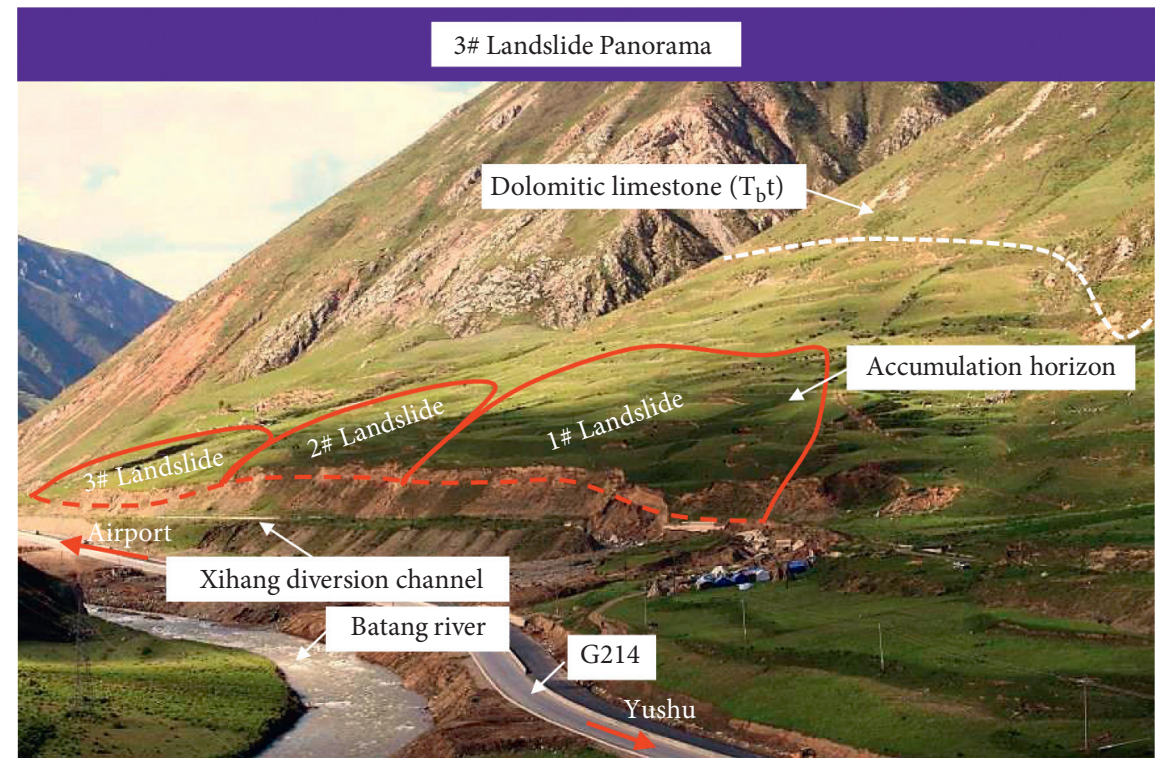

FIgURE 1: Overall view of Yushu Airport Road 3\# landslide.

The 2010 Yushu Earthquake was characterized by high intensity and frequent activity. It occurred in the GanziYushu fault zone $\left(\mathrm{F}_{2}\right)$ with an overall strike of $129^{\circ}$, an inclination of $84^{\circ}$, and a slip angle of $17^{\circ}$. The fault in this earthquake was nearly vertical and left-handed strike-slip, and it occurred with a rupture time of about $23 \mathrm{~s}$, a focal depth of $14 \mathrm{~km}$, and a rupture length of about $60 \mathrm{~km} \mathrm{[26].}$ The regional geological structure of Yushu County and the earthquake distributions of the 2010 Yushu Earthquake are shown in Figure 2.
2.2. Basic Overview of Yushu Airport Road 1\# Slider. The 1\# slider was destroyed under the earthquake, and a crack ran through the whole landslide at the rear edge of the front stage. The slope exit was about $30 \mathrm{~m}$ away, where the slope collapsed. A large collapsed area could be seen in the diversion canal of the Xihang Power Station, which is located on the outside of the landslide. The cracks in the back edge of the landslide were dense with a total width of $20 \mathrm{~m}$, an extension length of $50 \mathrm{~m}$, an average width of individual cracks of $20 \mathrm{~cm}-30 \mathrm{~cm}$, and a measurable depth of 


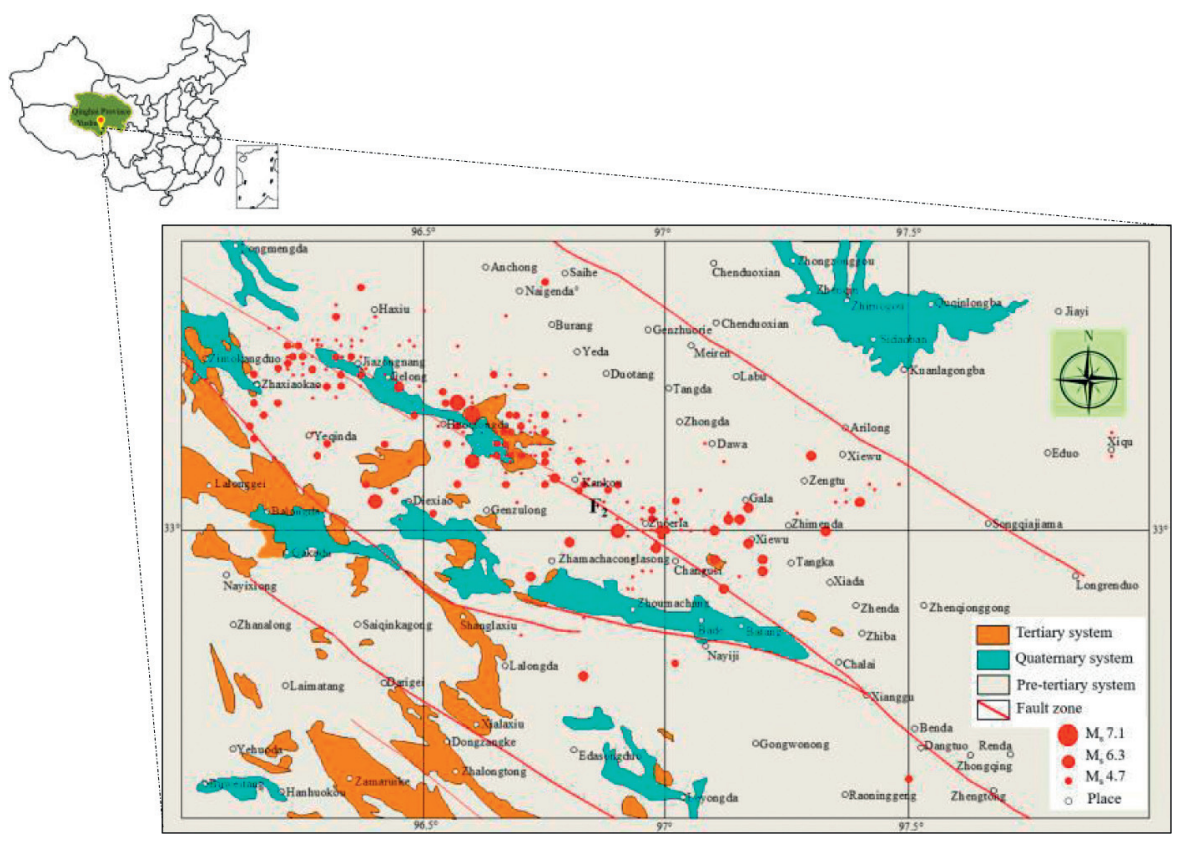

FIGURE 2: Regional geological structure and seismic distribution map of Yushu.

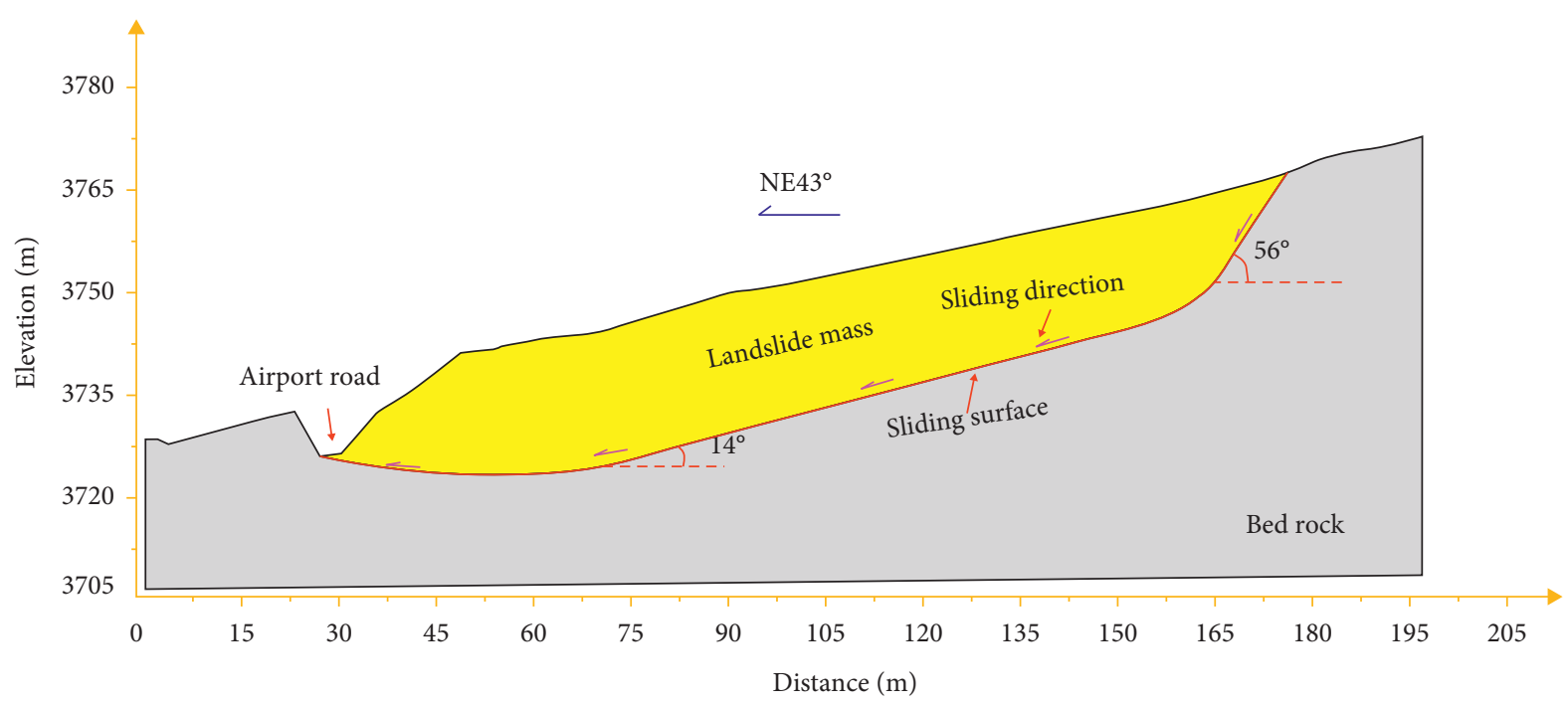

Silty clay $\left(\mathrm{Q}_{4}{ }^{\mathrm{C}+\mathrm{dl}}\right)$

Limestone $\left(\mathrm{T}_{3}{ }^{\mathrm{bt}}\right)$

FIgUre 3: Typical sectional view of 1\# slider on Yushu Airport Road.

$50 \mathrm{~cm}-60 \mathrm{~cm}$. The cracks were well-developed on the left side of the landslide, where the landslide exit was obscure. The representative section of the 1 \# slider was 2-2, as shown in Figure 3. This was the prototype of the shaking table test and numerical calculation, as shown in Figure 4.

Composed of predominantly silty clay, the landslide was from the Quaternary strata $\left(\mathrm{Q}_{4}{ }^{\mathrm{c}+\mathrm{dl}}\right)$. Local clay appearing light yellow, grayish brown, and plastic is purer, but most clays in the landslide were interlaced with slightly dense breccia and gravel (primarily limestone), accounting for

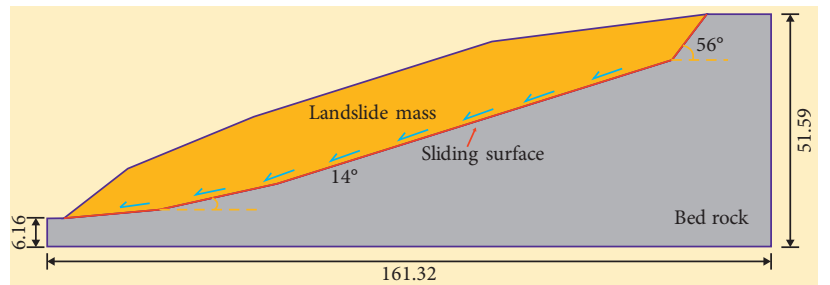

FIgURE 4: Model diagram of numerical calculation and the shaking table test. 
$10 \sim 20 \%$ of the total volume. The slope was stratified and continuous with inconsistent thicknesses. The Quaternary strata in the landslide were mainly of alluvial and diluvial origin, which contributed to the overall stability of the slope body.

The bedrock belonged to the Batang Group ( $\left.\mathrm{T}_{3} \mathrm{bt}\right)$. Its lithology was predominantly grey limestone with a small amount of slate and sandstone. The bedding was obvious, and the joints were developed. The main bedding was $220^{\circ} \angle 41^{\circ}$. The rock strata were outcropped on both sides of the Batang River with good stability.

\section{Influence of Vibration Frequency on Dynamic Stability of Slope Body}

3.1. Shaking Table Test. In this study, we designed a shaking table slope model (Figure 5), and the parameters of model soil are shown in Table 2. A laser displacement sensor was used to test the slope displacement. With sinusoidal acceleration excitation, the acceleration peak was set to be constant at $0.1 \mathrm{~g}$, and the action duration was set as $30 \mathrm{~s}$. The input waves of frequencies from $1 \mathrm{~Hz}$ to $10 \mathrm{~Hz}$ were applied, and the measured horizontal displacements at the slope top are shown in Figure 6.

It could be inferred from Figure 6 that when the peak time-history of input ground motion $(0.1 \mathrm{~g})$ was small, the slope stability was good without overall instability, and only local cracks occurred. Under such a circumstance, the effect of the slope body displacement was minor. When the frequency was $7 \mathrm{~Hz}$, the residual displacement of the slope began to decrease as the frequency rose.

Based on the distribution curve between the horizontal residual displacement and sine wave frequencies, the following relationship was obtained by linear numerical fitting:

$$
y=-00.1485 x+2.4187
$$

where $y$ represents the horizontal residual displacement and $x$ is the sine wave frequency.

3.2. Numerical Simulation Analysis. To further reveal the influence of vibration frequency on slope dynamic stability, FLAC $^{3 \mathrm{D}}$ was implemented for dynamic calculation and analysis. The FLAC ${ }^{3 \mathrm{D}}$ program can well simulate the mechanical behavior of failure or plastic flow of geological materials at the strength limit or yield limit, and it is very appropriate to analyze progressive failure and instability and simulating large deformation. 10 elastoplastic material constitutive models are involved in FLAC ${ }^{3 \mathrm{D}}$, including static, dynamic, creep, seepage, and temperature calculation ones. These models can integrate with each other to simulate various structural forms and solve complex geotechnical or mechanical problems. The inputs of FLAC ${ }^{3 \mathrm{D}}$ are different from those of a common numerical analysis program. They can be input either as typed words or commands, and the user could also write his/her own command stream for secondary development of the software based on the actual data. In this article, the authors developed a command stream for $\mathrm{FLAC}^{3 \mathrm{D}}$ analysis. The calculation model was based on 3\# landslide of Yushu Airport Road in Qinghai Province, as shown in Figure 4.

The Mohr-Coulomb constitutive model was used as the soil constitutive model. Based on the field investigation results, the calculation parameters were determined, as shown in Table 3.

Calculate the input acceleration time-history $\alpha_{t}$ with the following equation:

$$
\alpha_{t}=\sqrt{0.375 e^{-2.2 t} \cdot t^{8}} \cdot \sin (\omega \pi t),
$$

where $t$ is the time and $\omega$ is the frequency. When $\omega=2 \mathrm{~Hz}$, the time-history of the input ground motion was calculated, as shown in Figure 7.

The input ground motion frequency was set as $0.5 \mathrm{~Hz}$ and $1 \sim 15 \mathrm{~Hz}$ (with an interval of $1 \mathrm{~Hz}$ ), and the maximum residual displacement of the landslide under dynamic action was recorded, as shown in Figure 8.

According to the distribution curve between the two variables, we could conclude the following relationship by nonlinear numerical fitting:

$$
y=1.3316 x^{-0.918}
$$

where $y$ represents the maximum residual displacement and $x$ is the frequency.

\section{Discussion}

4.1. Calculation of the Seismic Coefficient of Ground Motion Time-History. The dynamic time-history measured by the shaking table test showed that the vibration frequency of simple harmonics had a significant positive impact on slope stability. The residual displacement of the slope (landslide) dropped obviously with higher vibration frequencies, indicating a significant increase in the slope stability.

Moreover, the seismic response time-history of the toe and top points of the slope was recorded, as shown in Figure 9. From the figure, it could be inferred that the acceleration time-history at the slope apex was hysteretic compared to the toe, suggesting that the seismic wave reached the slope toe first, propagated in the slope body and arrived at the slope top in the end. By comparing the waveforms of the toe and top of the slope, the propagation time in the slope body was calculated to be about $0.126 \mathrm{~s}$.

In fact, such a hysteresis effect exists in seismic wave propagation at the slope toe and top. When the slope is subjected to an earthquake, it always takes time for the seismic wave to spread. If such a time period is located near the peak of the input wave in the $-x$ direction (slope direction, Figure 10: $2.7 \mathrm{~s}-2.8 \mathrm{~s}$ ), the entire slope body could endure identical maximum seismic action along the $-x$ direction pointing outside of the slope, and it is at this situation that the slope is the most unstable. If the hysteretic period is located in the $+x$ direction of the input wave (Figure 10, $2.2 \mathrm{~s}-2.3 \mathrm{~s}$ ), the seismic action of the slope body would be directed to the slope simultaneously, which could promote slope stability. If the seismic action lasted for $1.95 \mathrm{~s} \sim 2.05 \mathrm{~s}$, it would be directed to the inside in some slopes but the outside in others. The two seismic action phases cancel out, 


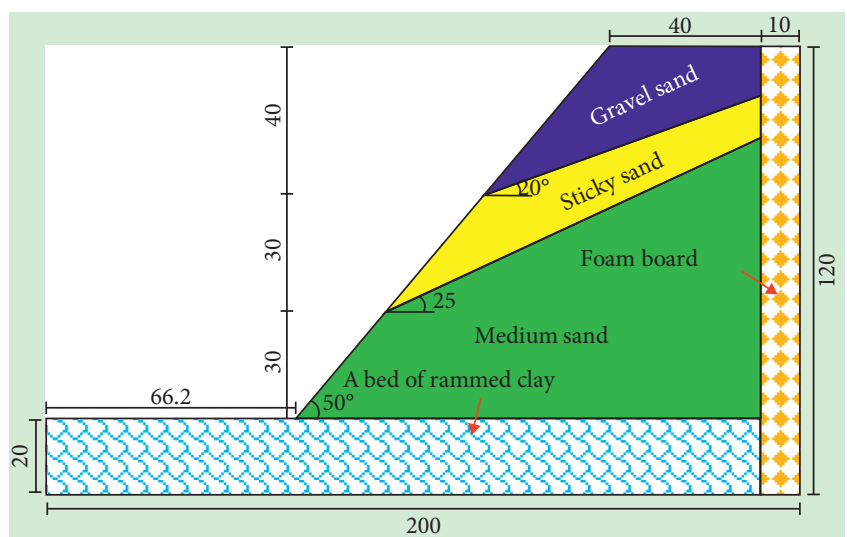

(a)

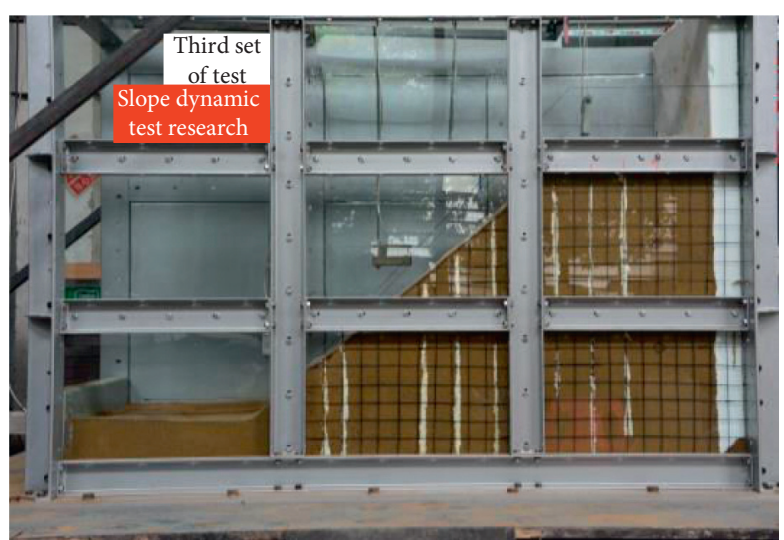

(b)

Figure 5: Vibration table slope model (unit: in $\mathrm{cm}$ ). (a) Model geometry. (b) Shaking table model.

TABLE 2: Basic parameters of the model soil material.

\begin{tabular}{lcccc}
\hline Item & Moisture content $(\%)$ & Compaction $\left(\mathrm{kN} / \mathrm{m}^{3}\right)$ & Cohesion $(\mathrm{kPa})$ & Internal friction angle $\left(^{\circ}\right)$ \\
\hline Middle sand & $6 \sim 8$ & $17.0 \sim 17.5$ & $10.0 \sim 14.0$ & $30 \sim 35$ \\
Clay sand & $12 \sim 14$ & $21.0 \sim 21.5$ & $65.0 \sim 75.0$ & $20 \sim 25$ \\
Gravel sand & $7 \sim 8$ & $19.0 \sim 20.0$ & $5.0 \sim 10.0$ & $35 \sim 40$ \\
\hline
\end{tabular}

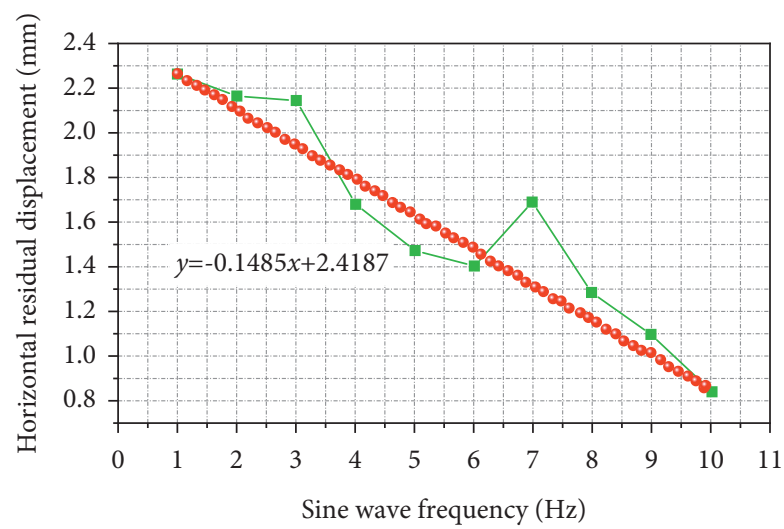

Figure 6: Horizontal residual displacement and frequency relationship.

TABLE 3: Rock mass calculation parameters.

\begin{tabular}{lccccc}
\hline Geotechnical types & Elastic modulus $(\mathrm{MPa})$ & Poisson's ratio & Cohesion $(\mathrm{kPa})$ & Internal friction angle $\left(^{\circ}\right)$ & $\mathrm{Gravity}\left(\mathrm{kN} / \mathrm{m}^{3}\right)$ \\
\hline Sliding body & 80 & 0.3 & 120 & 30 & 20 \\
Slip belt & 30 & 0.35 & 16 & 20 & 19 \\
Slide bed & 1000 & 0.25 & 200 & 38 & 21 \\
\hline
\end{tabular}

leading to a possible comprehensive seismic action of zero. Therefore, the slope stability is dependent on the comprehensive seismic action in the slope, which is related to the waveform characteristics in the seismic action period.

On the one hand, we assumed that the landslide could be horizontally divided into several soil strips, as shown in Figure 11, whose gravity was $G_{1}, G_{2}, \ldots, G_{n}$, respectively. The basic assumptions for such strip division are described below.
In a homogeneous slope, when the lowest point of the slip line is at the slope toe, the calculation results from the horizontal strip division method are consistent with those from the traditional vertical strip division method [27]. In other words, for a given uniform slip plane, its force distribution should be identical regardless of slip-plane segmentation methods [28]. The interslice force of the horizontal slicing method was also originated based on this idea. 


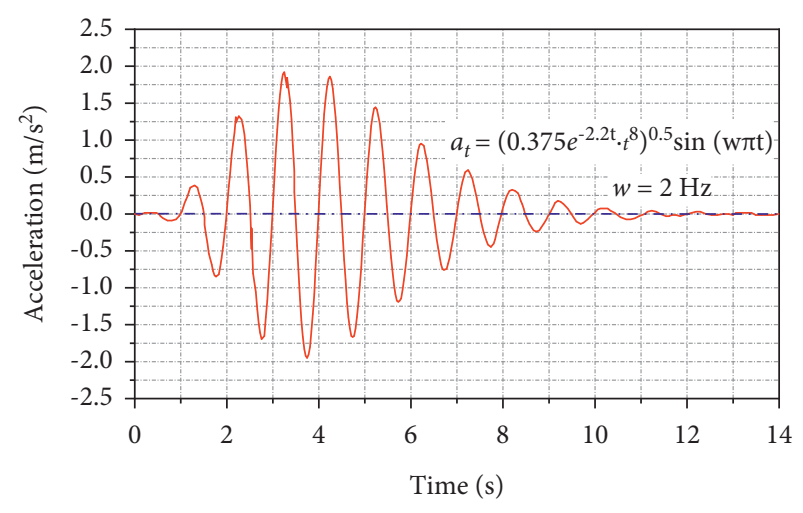

FIGURE 7: Input ground motion time-history $(\omega=2 \mathrm{~Hz})$.

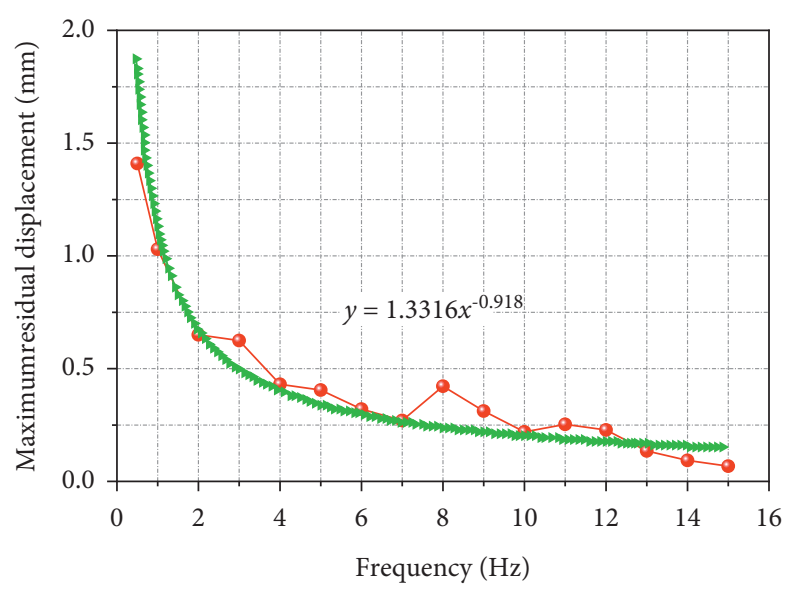

FIGURE 8: Residual displacement of landslide body under earthquake action.

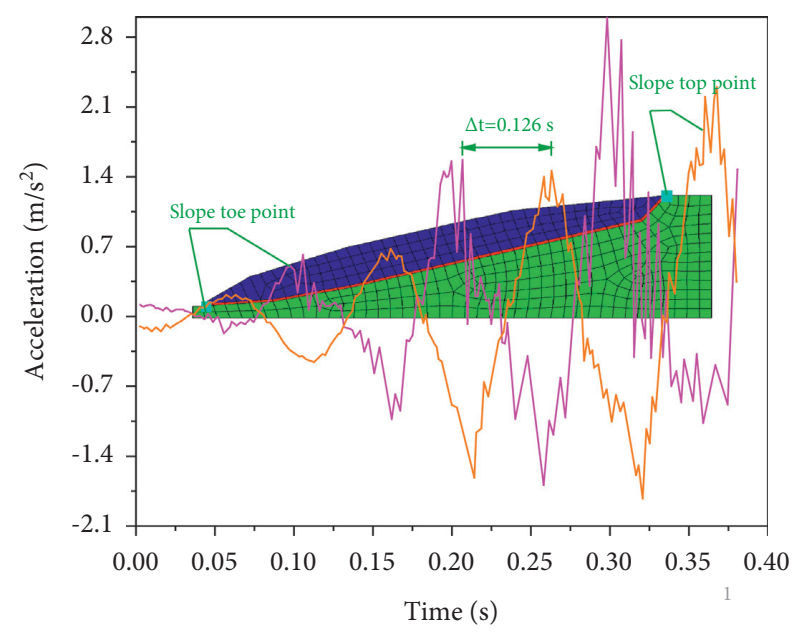

FiguRE 9: Characteristics of acceleration time-history curve.

Under seismic time-history, the seismic coefficients in each soil strip were $\alpha_{1}, \alpha_{2}, \ldots, \alpha_{n}$, respectively. Assuming that the total gravity of the sliding body was $G$ and the average seismic coefficient on the sliding body was $\bar{\alpha}$, then we can get

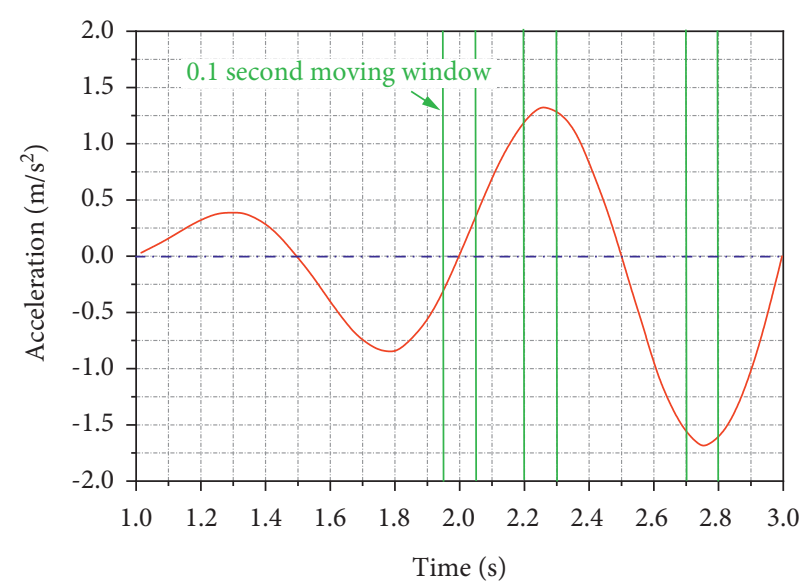

FIGURE 10: Time range magnification of ground motion $(\omega=2 \mathrm{~Hz})$.

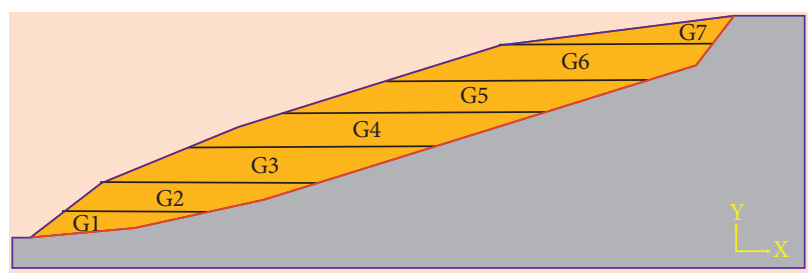

FIgURe 11: Slider horizontal bar graph.

$$
\alpha_{1} G_{1}+\cdots+\alpha_{n} G_{n}=\bar{\alpha} G .
$$

If the gravities of the soil strips were equal, then

$$
\begin{aligned}
G_{1}\left(\alpha_{1}+\cdots+\alpha_{n}\right) & =\bar{\alpha} G=\bar{\alpha} n G_{1}, \\
\bar{\alpha} & =\frac{\alpha_{1}+\cdots+\alpha_{n}}{n} .
\end{aligned}
$$

In other words, the average seismic coefficient on the sliding body is equal to the average seismic coefficient during the action period of the seismic wave.

Again, we would take 3\# landslide of Yushu Airport Road in this paper as an example. The distance from the slide toe to the slide top was $45.43 \mathrm{~m}$, and the seismic wave action lasted for $0.126 \mathrm{~s}$, giving us the seismic shear wave velocity of about $360 \mathrm{~m} / \mathrm{s}$. Such a result was consistent with the shear spread velocity of seismic waves in medium-density breccia described in the Specifications for Seismic Design of Railway Engineering (GB50111-2006). Therefore, our numerical simulation method is feasible to calculate the dynamic response of the landslide.

The input seismic wave was calculated by equation (2) with its frequencies changed to $0.5 \mathrm{~Hz}$ and $1 \sim 20 \mathrm{~Hz}$ with an interval of $1 \mathrm{~Hz}$. The average acceleration coefficient in the $0.126 \mathrm{~s}$ action period was calculated, and the acceleration time-history calculation results at $8 \mathrm{~Hz}$ are shown in Figure 12 . Within the first $0.126 \mathrm{~s}$, the average seismic coefficient was zero because the seismic wave had not propagated throughout the entire slope. As the seismic wave propagated in the slope, the average seismic coefficient rose gradually to its maximum at $4 \mathrm{~s}$ before dropping to zero again. 


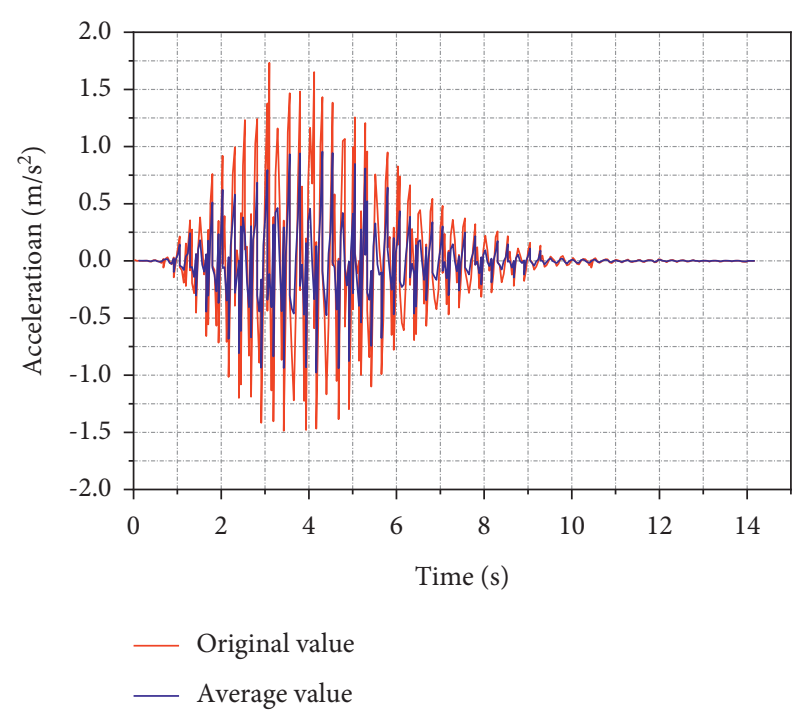

FIgURE 12: Time-history of ground motion $(\omega=8 \mathrm{~Hz})$.

The maximum input seismic time-history obtained from Figure 10 was compared with the maximum average seismic coefficient. As the frequency gradually increased from $1 \mathrm{~Hz}$ to $15 \mathrm{~Hz}$, the maximum average seismic coefficient dropped rapidly from $99.17 \%$ at $1 \mathrm{~Hz}$ to $2.61 \%$ at $15 \mathrm{~Hz}$. Furthermore, judging from Figures 8 and 13, we could consider that in the dynamic time-history analysis, the residual displacement of the landslide became smaller while the frequency of the input seismic wave rose due to the lower average acceleration that the slope body endured.

Therefore, in the pseudostatic analysis of the dynamic stability of landslides, the maximum average seismic coefficient within the ground motion period should be taken as the seismic coefficient.

Firstly, with the difference of slope height $\Delta H$ and the velocity of the seismic shear wave $v_{s}$, we could calculate the period of seismic action $\Delta t$ :

$$
\Delta t=\frac{\Delta H}{v_{s}}
$$

Then, in the earthquake time-history curve, the average acceleration at each moment $t$ was calculated from $\Delta t$ with a time period of $(t-\Delta t \sim t)$, and the average acceleration timehistory was established.

The ratio of the maximum average acceleration timehistory to the gravitational acceleration was taken as the input seismic coefficient of the pseudostatic method. The seismic force of the slope body was calculated following the equation of "Specifications for Seismic Design of Buildings (GB 50011-2010)" in Table 1, which was equivalent to the instantaneous most unfavorable state in seismic time-history analysis. The analysis results are still conservative. However, considering the influence of the dynamic time-history, they are more reasonable without the artificiality of empirical coefficients. In Figure 13, the frequency varied from $1 \mathrm{~Hz}$ to $15 \mathrm{~Hz}$, and the percentage of average seismic acceleration to the peak acceleration varied from $99 \%$ to $2.6 \%$. When the frequency was $12 \mathrm{~Hz}$, the percentage was about $26 \%$, which

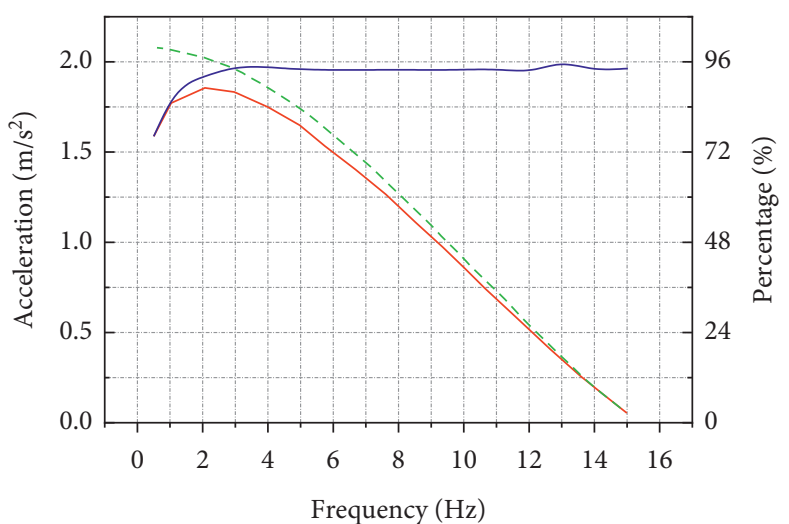

_ Maximum average acceleration

_ Input maximum time history

- - Percentage

FIGURE 13: Seismic acceleration change.

was equivalent to the comprehensive influence coefficient in the code of highway seismic design $\left(C_{z}=0.25\right)$.

4.2. Comparison and Validation with Previous Studies. In this section, we analyzed the pseudostatic stability of the landslide (Figure 4). The previously measured acceleration timehistory of ground motion [13] and the average acceleration time-history of $0.126 \mathrm{~s}$ are displayed in parallel (Figure 14). On the other hand, the previously measured seismic peak acceleration was $0.22 \mathrm{~g}$, and the average maximum acceleration in this article, which was defined as the ratio of dividing a period into the difference value between the absolute value of the positive and negative acceleration peaks, was $0.156 \mathrm{~g}$. According to the "China Earthquake Peak Acceleration Zoning Map [29]" and "Response to the Earthquake Fortification Standard for the Reconstruction after Yushu Earthquake," the seismic intensity that was approved as an area to fortify against earthquakes by the state was defined as the seismic fortification intensity, which could be generally used as the seismic basic intensity. The seismic fortification intensity of the Yushu Earthquake was $7^{\circ}$, and the designed earthquake acceleration was $0.15 \mathrm{~g}$.

The simplified Bishop method [30], the strict Janbu method [31], the Spencer method [32], and the transfer coefficient method [33] were used to calculate the dynamic stability of the landslide body. The calculation results are shown in Table 4.

Judging from Table 4, our calculation of the maximum average acceleration was close to the designed ground motion acceleration of $0.15 \mathrm{~g}$. In terms of stability, the result of GB50011-2010 was close to ours. Besides, the safety coefficient of landslides under earthquake was between 0.93 and 0.97 , which was in line with the seismic deformation and failure status of the landslide. The seismic coefficient of GB 50267-2019 was 0.225, and the corresponding seismic stability coefficient of the landslide was 0.82 . The seismic coefficients calculated from other codes were smaller, and the seismic stability coefficients of the landslide obtained from 


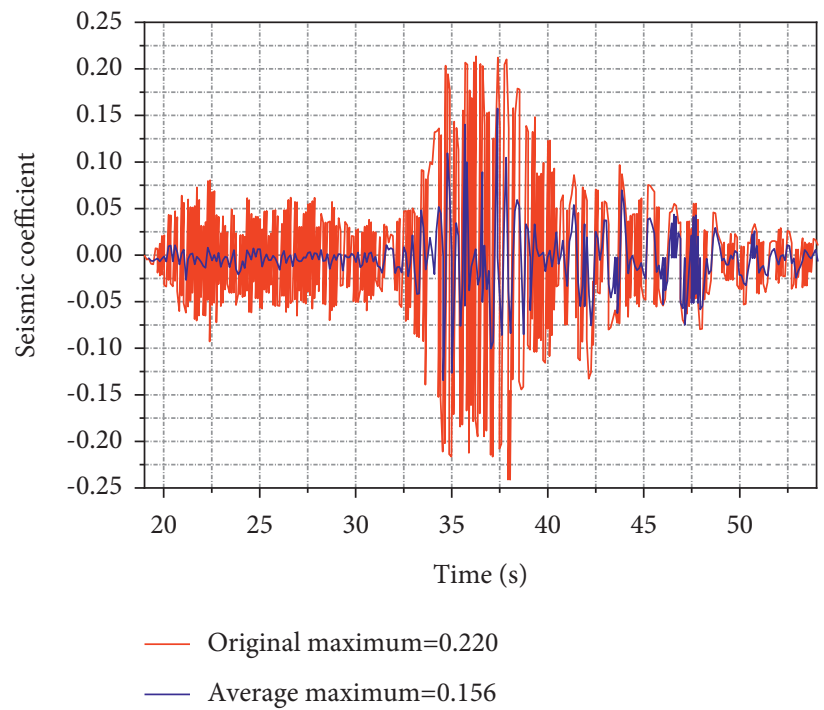

Figure 14: Yushu seismic waveform diagram.

TABLE 4: Calculation results of dynamic stability of landslides.

\begin{tabular}{|c|c|c|c|c|c|c|c|c|}
\hline $\begin{array}{l}\text { Calculation } \\
\text { method }\end{array}$ & $\begin{array}{c}\text { Natural } \\
\text { state }\end{array}$ & $\begin{array}{r}\text { Specific } \\
\text { seismic } \\
\text { for hi } \\
\text { enginee }\end{array}$ & $\begin{array}{l}\text { ation of } \\
\text { design } \\
\text { ghway } \\
\text { ing [14] }\end{array}$ & $\begin{array}{l}\text { Specifications for } \\
\text { seismic design of } \\
\text { hydraulic } \\
\text { structures [15] }\end{array}$ & $\begin{array}{l}\text { Specifications for } \\
\text { seismic design of } \\
\text { buildings [17] }\end{array}$ & $\begin{array}{l}\text { Specifications for } \\
\text { seismic design of } \\
\text { nuclear power } \\
\text { plants [18] }\end{array}$ & $\begin{array}{l}\text { Specifications for } \\
\text { seismic design of } \\
\text { railway } \\
\text { engineering [19] }\end{array}$ & $\begin{array}{l}\text { This } \\
\text { paper }\end{array}$ \\
\hline $\begin{array}{l}\text { Coefficient } \\
\text { values }\end{array}$ & & $C_{i}=0.6$ & $C_{i}=1.7$ & $a_{i}=1.0$ & $a_{1}=0.15$ & $a=0.15$ & $A_{\mathrm{g}}=0.22 \mathrm{~g}$ & $\bar{\alpha}=0.156$ \\
\hline $\begin{array}{l}\text { Seismic } \\
\text { coefficient }\end{array}$ & 0 & 0.023 & 0.064 & 0.038 & 0.15 & 0.225 & 0.055 & 0.156 \\
\hline $\begin{array}{l}\text { Bishop } \\
\text { method }\end{array}$ & 1.519 & 1.405 & 1.236 & 1.338 & 0.982 & 0.827 & 1.270 & 0.967 \\
\hline $\begin{array}{l}\text { Janbu } \\
\text { method }\end{array}$ & 1.529 & 1.410 & 1.236 & 1.341 & 0.975 & 0.819 & 1.271 & 0.961 \\
\hline $\begin{array}{l}\text { Spencer } \\
\text { method }\end{array}$ & 1.512 & 1.394 & 1.224 & 1.329 & 0.969 & 0.815 & 1.258 & 0.955 \\
\hline $\begin{array}{l}\text { Transfer } \\
\text { coefficient } \\
\text { method }\end{array}$ & 1.310 & 1.238 & 1.125 & 1.195 & 0.938 & 0.812 & 1.149 & 0.927 \\
\hline
\end{tabular}

other codes were greater than 1.2 , which was inconsistent with the current seismic deformation and failure of the landslide.

\section{Conclusions}

With Yushu Airport Road 3\# landslide as an example, this paper presented a method to calculate the equivalent seismic coefficient based on the dynamic propagation process with a shaking table test and numerical dynamic time-history analysis. Besides, the seismic coefficients of slope dynamic stability analysis were discussed, and the following conclusions were obtained:

(1) With greater vibration frequencies, the residual slope displacement decreased obviously, but the slope stability was strengthened. Besides, the average acceleration of slope seismic action decreased gradually as the input seismic wave frequency rose.
(2) In the pseudostatic method for dynamic stability analysis of landslides, the maximum average seismic coefficient within the duration of ground motion is recommended to be considered the seismic coefficient.

(3) The safety factor of landslide obtained by our pseudostatic method was close to that obtained from GB50011-2010 under an earthquake, and our method resembles better to the actual situation of earthquake deformation and failure of landslide compared to the existing standards [34].

\section{Data Availability}

Some or all data, models, or code generated or used during the study are available from the corresponding author upon request.

\section{Conflicts of Interest}

The authors have no conflicts of interest to declare. 


\section{Acknowledgments}

The authors gratefully acknowledge the financial support by the National Key R\&D Program of China (no. 2018YFC1504901) and Natural Science Foundation of Gansu Province (no. 145RJZA068).

\section{References}

[1] C. Romer and M. Ferentinou, "Numerical investigations of rock bridge effect on open pit slope stability," Journal of Rock Mechanics and Geotechnical Engineering, vol. 11, no. 6, pp. 1184-1200, 2019.

[2] S. A. Sepúlveda and A. Serey, "Tsunamigenic, earthquaketriggered rock slope failures during the April 21, 2007 Aisén earthquake, southern Chile (45.5 S)," Andean Geology, vol. 36, no. 1, pp. 131-136, 2009.

[3] W. S. Freeman and H. B. Sutherland, "Slope stability analysis in anisotropic winnipeg clays," Canadian Geotechnical Journal, vol. 11, no. 1, pp. 59-71, 1974.

[4] N. M. Newmark, "Effects of earthquakes on dams and embankments," Géotechnique, vol. 15, no. 2, pp. 139-160, 1965.

[5] R. W. Jibson and M. W. Jibson, Java Programs for using Newmark's Method and Simplified Decoupled Analysis to Model Slope Performance during Earthquakes, US Geological Survey, Reston, VA, USA, 2003.

[6] K. Terzaghi, Mechanism of Landslides, Department of Engineering, Harvard University, Boston, MA, USA, 1951.

[7] S. Utili and A. H. Abd, "On the stability of fissured slopes subject to seismic action," International Journal for Numerical and Analytical Methods in Geomechanics, vol. 40, no. 5, pp. 785-806, 2016.

[8] D. J. Li, L. H. Zhao, L. Li, and X. Cheng, "Upper limit analysis of the influence of nonlinear shear strength parameters on the stability of crack slope under seismic effect," Rock and Soil Mechanics, vol. 36, no. 5, pp. 1313-1321+1327, 2015, in Chinese.

[9] T. K. Nian, K. Liu, D. F. Zheng, and G. Q. Chen, "Limit analysis of anchored slopes subjected to seismic loading," Advances in Soil Dynamics and Foundation Engineering, ASCE, Reston, VA, USA, pp. 548-553, 2014.

[10] C. M. Jadar and S. Ghosh, "Seismic bearing capacity of shallow strip footing using horizontal slice method," International Journal of Geotechnical Engineering, vol. 11, no. 1, pp. 38-50, 2016.

[11] S. S. Nimbalkar, D. Choudhury, and J. N. Mandal, "Seismic stability of reinforced-soil wall by pseudo-dynamic method," Geosynthetics International, vol. 13, no. 3, pp. 111-119, 2006.

[12] A. Izadi, N. S. S. Mahsa, R. Jamshidi Chenari, and A. Ghorbani, "Pseudo-static bearing capacity of shallow foundations on heterogeneous marine deposits using limit equilibrium method," Marine Georesources and Geotechnology, vol. 8, no. 6, pp. 1-12, 2019.

[13] T. Yang, L. Huang, J. Feng, H. G. Wu, and Z. K. Qi, “Dynamic stability analysis of landslide based on seismic propagation process," Rock and Soil Mechanics, vol. 38, no. 9, pp. 27082712, 2017, in Chinese.

[14] Highway Planning and Design Institute of Ministry of Communications, JTG B02-2013 Specification of Seismic Design for Highway Engineering, People's Communications Press, Beijing, China, 2013, in Chinese.

[15] China Institute of Water Resources and Hydropower Research, GB51247-2018 Specifications for Seismic Design of
Hydraulic Structures, China Planning Publishing House, Beijing, China, 2018, in Chinese.

[16] L. W. Chen, "Block-type slope movement," Dictionary Geotechnical Engineering/Wörterbuch GeoTechnik, vol. 20, no. 2, p. 140, 2014, in Chinese.

[17] China Academy of Building Research, GB 50011-2010 Specifications for Seismic Design of Buildings, China Building Industry Press, Beijing, China, 2010, in Chinese.

[18] Institute of Engineering Mechanics, China Earthquake Administration, GB 50267-2019 Specifications for Seismic Design of Nuclear Power Plants, China Planning Publishing House, Beijing, China, 2019, in Chinese.

[19] China Railway No. 1 Survey and Design Institute Group Co. Ltd., GB50111-2006 Specifications for Seismic Design of Railway Engineering, China Planning Publishing House, Beijing, China, 2009, in Chinese.

[20] Y. Zou, H. Liu, L. Jing, and J. Cui, “A pseudo-static method for seismic responses of underground frame structures subjected to increasing excitations," Tunnelling and Underground Space Technology, vol. 65, pp. 106-120, 2017.

[21] L. Bodström, "Swedish university policy: the 1955 commission on the Swedish universities," Minerva, vol. 3, no. 1, pp. 83-90, 1964.

[22] A. W. Bishop, "The use of the slip circle in the stability analysis of slopes," Géotechnique, vol. 5, no. 1, pp. 7-17, 1955.

[23] E. Hoek and J. Bray, "Rock slope engineering," Publication of Institution of Mining \& Metallurgy, CRC Press, vol. 37, pp. 124-140, Boca Raton, FL, USA, 2nd edition, 1977.

[24] S. Kramer, Geotechnical Earthquake Engineering, PrenticeHall, Hoboken, NJ, USA, 1996.

[25] J. J. Clague and S. Douglas, Landslides: Types, Mechanisms and Modeling, Cambridge University Press, Cambridge, UK, 2012.

[26] Y. Zhang, L. Xu, and Y.-T. Chen, "Source process of the 2010 Yushu, Qinghai, earthquake," Science China Earth Sciences, vol. 53, no. 9, pp. 1249-1251, 2010.

[27] M. Shahgholi, A. Fakher, and C. Jones, "Horizontal slice method of analysis," Géotechnique, vol. 52, no. 9, pp. 697-699, 2002.

[28] Z. B. Wang, L. Li, X. L. Yang, and J. F. Zou, "Application of horizontal segment method in stability analysis of high filling embankment," China Journal of Highway and Transport, vol. 20, no. 3, pp. 29-34, 2007.

[29] China Earthquake Administration, GB18306-2015 China Earthquake Peak Acceleration Zoning Map, China Standard Press, Beijing, China, 2016, in Chinese.

[30] S. M. Yoder and T. C. Hopkins, "Slope stability analysis: a computerized solution of bishop's simplified method of slices," Computer Programs, vol. 358, Article ID 13023, 1973.

[31] T. Yamagami and Y. Ueta, "Noncircular slip surface analysis of the stability of slopes. An application of dynamic programming to the Janbu method," Landslides, vol. 22, no. 4, pp. 8-16, 1986.

[32] J. L. Rayces and L. Lebich, "Experiments on constrained optimization with Spencer's method," Optical Engineering, vol. 27, no. 12, Article ID 121031, 1988.

[33] I. J. Dunn and A. Einsele, "Oxygen transfer coefficients by the dynamic method," Journal of Applied Chemistry and Biotechnology, vol. 25, no. 9, pp. 707-720, 1975.

[34] Ministry of Housing and Urban-Rural, Development of the People's Republic of China, Bid Letter [2010]122 Response to the Earthquake Fortification Standard for the Reconstruction of Yushu Earthquake after the Earthquake, Ministry of Housing and Urban-Rural, Development of the People's Republic of China, Beijing, China, 2010, in Chinese. 